\title{
CARTOGRAFIA GEOMORFOLÓGICA NA BACIA DO RIBEIRÃO CARANGUEJO: SUBSÍDIO PARA O ESTUDO DO RELEVO NA ZONA DA MATA MINEIRA
}

\author{
Derik Ribeiro de Paiva $^{(a)}$, Roberto Marques Neto ${ }^{(b)}$ \\ (a) Departamento de Geociências, Universidade Federal de Juiz de Fora, geoderik@ gmail.com \\ (b) Departamento de Geociências, Universidade Federal de Juiz de Fora, roberto.marques@ufjf.edu.br
}

Eixo: SISTEMAS GEOMORFOLÓGICOS: ESTRUTURA, DINAMICAS E PROCESSOS

\begin{abstract}
Resumo
A crescente pressão sobre os recursos ambientais impetrada pelo modelo econômico de produção atualmente vigente impõe a necessidade do desenvolvimento de subsídios ao planejamento das paisagens. Partindo da compreensão da cartografia geomorfológica como um aporte metodológico substancial não só para a Geomorfologia em si, como também para os demais campos do conhecimento científico que se ocupam do planejamento em suas distintas esferas de atuação, o presente artigo tem como objetivo geral a realização de um estudo do sistema geomorfológico da bacia hidrográfica do ribeirão Caranguejo, localizada na Zona da Mata Mineira, tendo como aporte a cartografia geomorfológica. Como metodologia adotou-se a proposta elaborada no âmbito do IBGE, cujo princípio básico trata-se da ordenação dos fatos geomorfológicos conforme uma classificação que leva em consideração aspectos temporais e espaciais, e que viabiliza a distinção dos modelados como unidade básica do relevo, bem como os grupamentos que mantém relações hierárquicas com essas unidades básicas. Dessa forma, foram identificados os tipos de modelados, sendo estes posteriormente diferenciados e caracterizados de acordo com fatores intrínsecos à sua natureza estrutural, litológica, pedológica, climática e morfodinâmica.
\end{abstract}

Palavras Chave: Cartografia Geomorfológica - Bacia Hidrográfica - Planejamento

\section{INTRODUÇÃO}

A geomorfologia, ciência cujo intento é direcionado para a análise e interpretação da gênese, formas e processos responsáveis pela formação das paisagens terrestres, tem na cartografia geomorfológica um dos seus principais aportes teórico metodológicos. Segundo Klimaszewski (1982, apud FLORENZANO, 2008) o marco inicial do desenvolvimento dessa salutar técnica de representação espacial do relevo remonta ao ano de 1914, quando da publicação do Morphologischer Atlas (Atlas Morfológico) elaborado por Siegfried Passarge. Conforme contextualiza Coltrinari (2011), nas décadas posteriores à publicação levada a efeito por Passarge, não foi dada a cartografia geomorfológica a devida atenção até o findar da Segunda Guerra Mundial (1939-1945), quando especialistas em planejamento, dentre outras áreas, passaram a atentar para a demanda por documentos cartográficos de ratificada precisão.

A partir desse momento histórico a cartografia geomorfológica passa a ser alvo da atenção de vários pesquisadores oriundos de distintas escolas científicas, corroborando no desenvolvimento de variadas metodologias de classificação dos fatos geomorfológicos. Essa pluralidade de técnicas teve 
como consequência uma falta de isonomia no que tange à elaboração desses documentos, sendo esta questão considerada por muitos autores como um dos maiores percalços enfrentados por esse ramo da pesquisa geomorfológica (ROSS, 1991; CUNHA, 2003; ARGENTO, 1995).

O crescente interesse na representação dos aspectos do relevo tem como justificativa a ampla gama de possibilidades de aplicação dos produtos oriundos dessa técnica cartográfica no que se refere ao planejamento urbano, agrário, ambiental e territorial. Diante disso, a demanda por documentos cartográficos que subsidiem os processos de intervenção no relevo tem aumentado, exaltando a necessidade dos pesquisadores que atuam na área de estarem sempre atentos a novas tecnologias e metodologias que possam aprimorar o processo de cartografação do relevo nas variadas escalas de análise intrínsecas à ciência geomorfológica.

Frente a essa realidade, se fazem de substancial importância os esforços em prol da pesquisa e desenvolvimento voltados para a produção de mapas e cartas geomorfológicas em escala grande, visando que estas possam vir a subsidiar o processo decisório, em escala local, acerca da disposição espacial e tipos de intervenção passíveis ou não de serem desenvolvidas no local em questão. Assim, o presente artigo tem como objetivo geral realizar um estudo do sistema geomorfológico da bacia hidrográfica do ribeirão Caranguejo (BHRC), tendo como aporte metodológico a cartografia geomorfológica.

\section{METODOLOGIA}

Para viabilizar o cumprimento dos objetivos supramencionados, foi adotada como concepção teórica a perspectiva sistêmica, conforme explicitada por Christofoletti (1999), uma vez que esta possibilita a realização de uma interpretação integrada de bacias hidrográficas como um sistema processo-resposta, ou seja, um sistema ambiental susceptível a pressões e impactos oriundos da esfera socioambiental, onde este responderá de forma particularizada a um determinado evento, impacto ou alteração que seja lhe imposto. Para esta análise proposta, torna-se oportuna a adoção da abordagem geográfica (CHRISTOFOLETTI, 1999), tendo em vista que ela viabiliza a análise e compreensão da área foco da pesquisa a partir de um relacionamento de seus fatores abióticos, bióticos e antrópicos.

Para elaboração da carta geomorfológica da BHRC foi utilizado como referência o sistema metodológico desenvolvido no âmbito do Instituto Brasileiro de Geografia e Estatística (NUNES et al. 1994). Conforme essa proposta metodológica, a primeira etapa é referente à leitura, análise e interpretação de fontes bibliográficas e cartográficas preexistentes acerca da região, assim como a elaboração e edição de documentos cartográficos que darão subsídio à elaboração da carta geomorfológica.

Posteriormente, no plano das unidades de relevo, foi realizada a medição da profundidade de dissecação e da dimensão interfluvial de todas as geoformas denudacionais da bacia. Estas foram mensuradas, em metros, a partir das folhas topográficas 1: 50.000 o IBGE que abrangem a área (SF- 
23-X-D-I4, Rio Pomba; SF-23-X-D-I-3, Paiva; SF-23-X-D-IV-I, Juiz de Fora). A incisão vertical foi quantificada a partir do estabelecimento da amplitude altimétrica entre os topos e os fundos de vale de referência. Para a dimensão interfluvial foi executada a medição da extensão da faixa divisória verificável entre as linhas de drenagem posicionadas na base de duas vertentes opostas ou entre duas nascentes.

A partir da interpretação concomitante da morfometria e de informações referentes à declividade local, seguida da seleção e inserção dos símbolos alusivos à representação de níveis taxonômicos mais detalhados, foram distintos os modelados de dissecação e de agradação, sendo estes a base para o estabelecimento dos padrões de formas semelhantes em consonância aos níveis taxonômicos de Tricart (1965), adaptados por Ross (1992). A delimitação dos tipos de modelado segundo os padrões de formas trata-se de um procedimento remetente ao terceiro nível de grandeza têmporo-espacial de Ross (1992). Os parâmetros morfométricos foram representados na legenda em quadro a parte conforme a proposta de Nunes et al. (1994), que prescreve a construção de um quadro síntese para os padrões morfométricos dos diferentes tipos de modelado, no qual a dimensão interfluvial é plotada nas colunas e a profundidade de dissecação nas linhas.

Sobre os modelados de dissecação poligonizados foram inseridos símbolos alfa-numéricos, adotando-se o sistema de letras padrão, iniciado por letra maiúscula que diferencia os modelados de dissecação (D) e agradação (A) e seguido pelas minúsculas específicas às formas de relevo mapeadas. Em associação foram inseridos ao lado das letras os números provenientes da morfometria das morfologias denudacionais previamente quantificadas. Em um segundo nível de abordagem foram inseridos símbolos representativos de feições do relevo e de processos não passiveis de representação na escala trabalhada, procedimento este que viabiliza a representação de fatos geomorfológicos individuais em sua forma e extensão.

O produto cartográfico final foi digitalizado em software ArcGis, apresentando-se o mapa e a legenda em figuras separadas em função do grande número de informações inerentes ao corpo da legenda, procedimento que tem por finalidade facilitar a leitura da mesma, constituída por associações de cores, recursos textuais, códigos alfanuméricos e demais simbologias que permitem uma compatibilização entre os níveis taxonômicos e as feições geomórficas de mapeamento exequível.

Concomitante à sequência de procedimentos cartográficos anteriormente mencionados, foram realizadas incursões a campo para reconhecimento e interpretação do relevo, sendo estes de substancial importância para o mapeamento, bem como para embasar uma discussão plausível acerca do quadro geomorfológico local, pautada no reconhecimento de formas, processos e coberturas superficiais. 


\section{LOCALIZAÇÃO E CARACTERIZAÇÃO DA ÁREA}

A bacia hidrográfica do ribeirão Caranguejo (BHRC) está localizada na microrregião de Juiz de Fora, mesorregião da Zona da Mata do estado de Minas Gerais (Figura 1), compreendida entre as

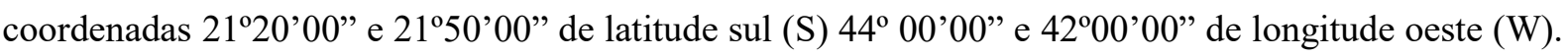
A área da bacia abrange a parte oeste do município de Rio Novo, parte nordeste do município de Piau e uma pequena área ao sul do território de Tabuleiro.

O ribeirão Caranguejo é um afluente do rio Novo cujas nascentes se localizam na Serra dos Almeidas, na porção oeste da bacia. O rio Novo é um dos mais importantes tributários do rio Pomba, que por sua vez integra a bacia do rio Paraíba do Sul, componente da região hidrográfica do Atlântico Sudeste brasileiro. A bacia hidrográfica foco do presente artigo possui área equivalente a $164 \mathrm{~km}^{2}$. Sua nascente principal está localizada nos limites do município de Piau, a uma altitude aproximada de 700 metros, sendo sua foz posicionada a 390 metros acima do nível do mar próxima à área urbana do município de Rio Novo.

A bacia hidrográfica em menção está situada no setor central da Província Mantiqueira, em litologias do Complexo Juiz de Fora. Em sua área de abrangência tem-se como litologia predominante a ocorrência de gnaisses. Os gnaisses são rochas constituídas por diversos minerais, predominantemente compostos por feldspato e quartzo, com no mínimo $20 \%$ de feldspato em volume, havendo também a ocorrência de plagioclásio e biotita. São rochas de grande variação mineralógica e grau de metamorfismo. A estrutura bandada é comum, sendo considerada por algumas classificações como essencial para a sua definição. De maneira mais abrangente, é a composição quartzo-feldspática e a foliação gnáissica que os caracterizam (TEIXEIRA et al, 2000).

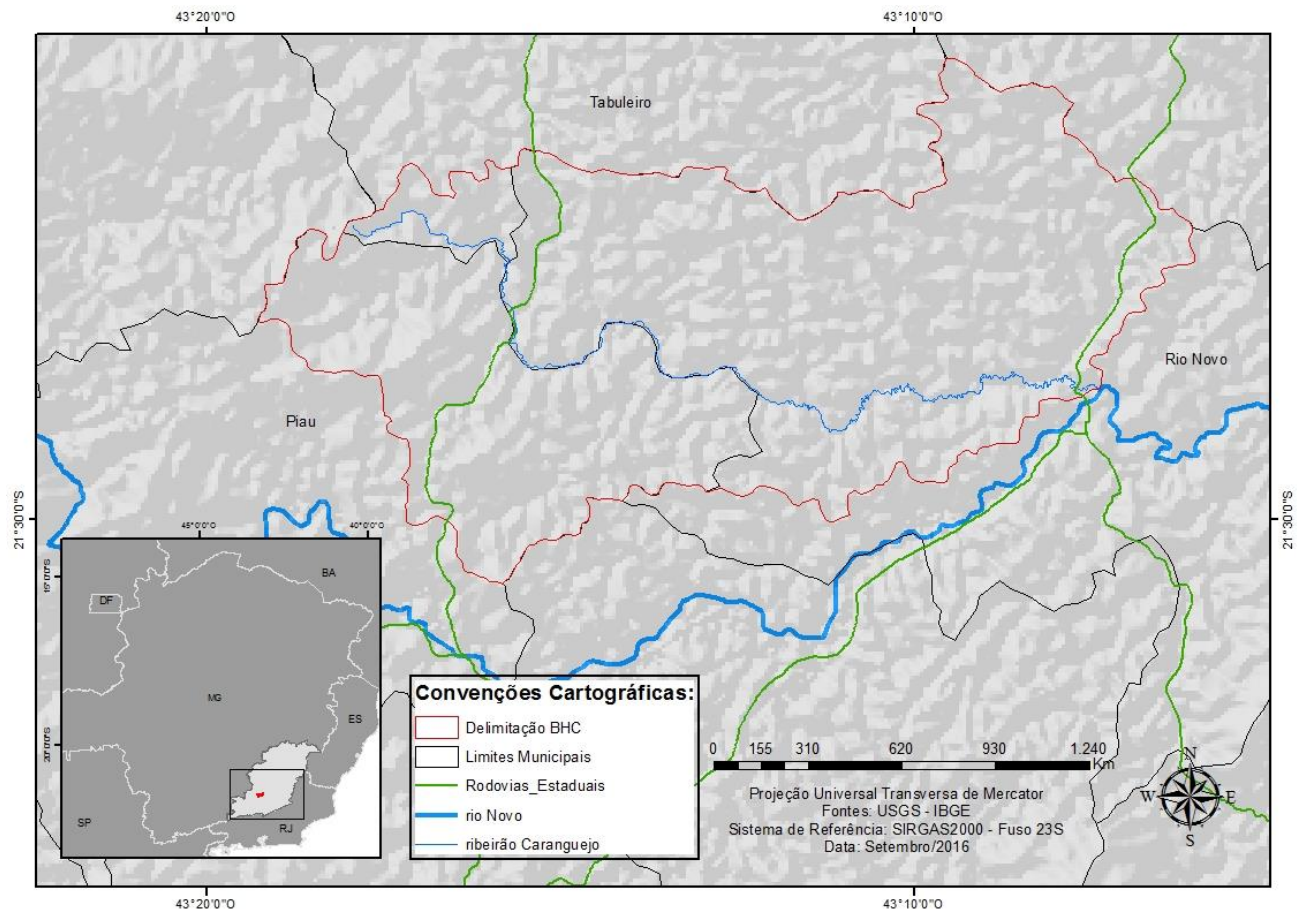

Figura 01: Bacia Hidrográfica do ribeirão Caranguejo. 
A litologia gnáissica define um tipo de relevo muito comum no domínio tropical atlântico, caracterizada por Ab’Saber (1966) como Domínio dos Mares de Morros Florestados, sendo estas áreas caracterizadas por serem zonas de decomposição profunda das rochas, o que viabiliza a formação de mantos de intemperismo também profundos com saprolitos bem desenvolvidos. Esses saprolitos ocasionalmente se pedogenizam em Latossolos ou coberturas argilosas latossólicas, que costumam aparecer associadas a Cambissolos e Neossolos devido à movimentação topográfica regional.

De acordo com a classificação de W. Koeppen o clima da região é designado como do tipo Tropical Úmido-Seco (Cwa), de inverno seco e verão chuvoso, com quatro a cinco meses secos, ou seja, clima mesotérmico com verões quentes e estação chuvosa também no verão. O padrão climático local, associado ao relevo predominantemente composto por morros, bem como à presença de Latossolos, engendravam na região uma cobertura florestal compatível com o substrato argiloso existente. Dessa forma, a área cerne da presente pesquisa encontra-se situada na região da Mata Atlântica. Segundo o Manual Técnico da Vegetação Brasileira (IBGE, 2012), a cobertura vegetal característica da região é composta por Floresta Estacional Semidecidual (Floresta Tropical Subcaducifólia).

Conforme observado por Valverde (1958, p.105), "de um modo geral, aí, todas as indicações levam a concluir que o revestimento natural era o de uma mata contínua". Porém, atualmente tem-se o predomínio de uma paisagem fitogeográfica bastante alterada pela inserção de pastagens com gramíneas exóticas. Quanto a isso, Valverde (op. cit), ao realizar pesquisas na Zona da Mata Mineira, às vésperas do início da década de sessenta, já nos atentava para o paradoxo existente em se denominar Zona da Mata uma região cuja paisagem teve sua vegetação amplamente suprimida, afirmando que "por toda parte, o homem substituiu o manto escuro das florestas pelo pasto claro e aveludado do capim-gordura". Assim, a atual cobertura vegetal da região é predominantemente composta por pastagens e silvicultura de eucaliptos.

\section{RESULTADOS E DISCUSSÕES}

A bacia hidrográfica do ribeirão Caranguejo encontra-se inserida no contexto do domínio dos "mares de morros", tendo como principal responsável pela configuração do relevo e da rede hidrográfica da região a disposição das linhas de falha integrantes do Domínio das Faixas de Dobramentos Remobilizados, sendo que o tronco coletor principal obedece a uma orientação preferencial no sentido sudoeste.

A referida bacia localiza-se no médio curso do rio Novo, sendo uma região caracterizada por intensa dissecação fluvial. Nas proximidades das nascentes da bacia tem-se a ocorrência de morfologias associadas ao Complexo Serra da Mantiqueira. Como características intrínsecas a essas morfologias destacam-se a presença de escarpas muito dissecadas com vertentes íngremes e topos aguçados e declividades agudas. 
OS DESAFIOS DA GEOGRAFIA FÍSICA NA FRONTEIRA DO CONHECIMENTO

Instituto de Geociências - Unicamp Campinas - SP

28 de Junho à 02 de Julho de 2017

No contexto do médio rio Novo, onde está posicionada a bacia do ribeirão Caranguejo, tem-se a ocorrência de um compartimento geomorfológico referente aos Planaltos Dissecados do Centro-Sul e Leste de Minas, caracterizado pela presença de colinas, cristas e morros oriundos do trabalho imposto pela dissecação fluvial, ou seja, morfologias mamelonizadas advindas do intenso processo de dissecação e degradação do relevo. Segundo o RADAMBRASIL (1983), a presença de colinas e cristas mais ou menos alinhadas reflete "o alto controle geológico disposto em um conjunto de falhas e fraturas" (RADAMBRASIL, 1983, p.340), refletindo assim um forte controle estrutural. O sentido das cristas está disposto conforme a orientação predominante das principais falhas. Perturbações tectônicas cenozoicas ocorridas na região podem ser verificadas pela presença de vales estruturais e escarpas escalonadas e desalinhadas (RADAMBRASIL,1983).

A partir desse breve preâmbulo acerca do contexto geomorfológico ao qual está inserida a área foco do presente estudo, apresenta-se aqui o mapa geomorfológico da bacia hidrográfica do ribeirão Caranguejo (figura 02), sendo sua legenda disposta em figura a parte (figura 03), conforme prescrito por Nunes et.al (1994).

O mapa revela de forma explícita que, a partir do exutório em direção para oeste, o domínio de um modelado de dissecação mais suave e homogêneo dá lugar paulatinamente a um sistema geomorfológico de maior energia à medida que se aproxima das áreas de nascentes, devido ao aumento do controle estrutural na porção oeste da bacia. Assim, tem-se na área compreendida pela referida bacia um predomínio de orientação das estruturas no sentido nordeste/sudoeste. Há também a presença de orientações no sentido noroeste/sudeste, referentes a campos de tensão neotectônicos mais recentes, implicando em compressões no sentindo leste/oeste.

Conforme ilustra o mapeamento realizado na bacia hidrográfica do ribeirão Caranguejo, percebe-se que esta tem seu relevo predominantemente composto por morrotes (Dmr) e morros alongados (Dma). Quanto aos morrotes, salienta-se aqui os distintos vínculos genéticos existentes entre eles, sendo os localizados na parte baixa da bacia produtos da intensa dissecação em caráter mais homogêneo, dendritificando os padrões de drenagem, ao passo que os que se encontram a oeste são associados aos modelados de dissecação em controle estrutural, onde a dissecação fluvial promoveu um reafeiçoamento de patamares do relevo em morfologias com atributos característicos de morros e morrotes. 


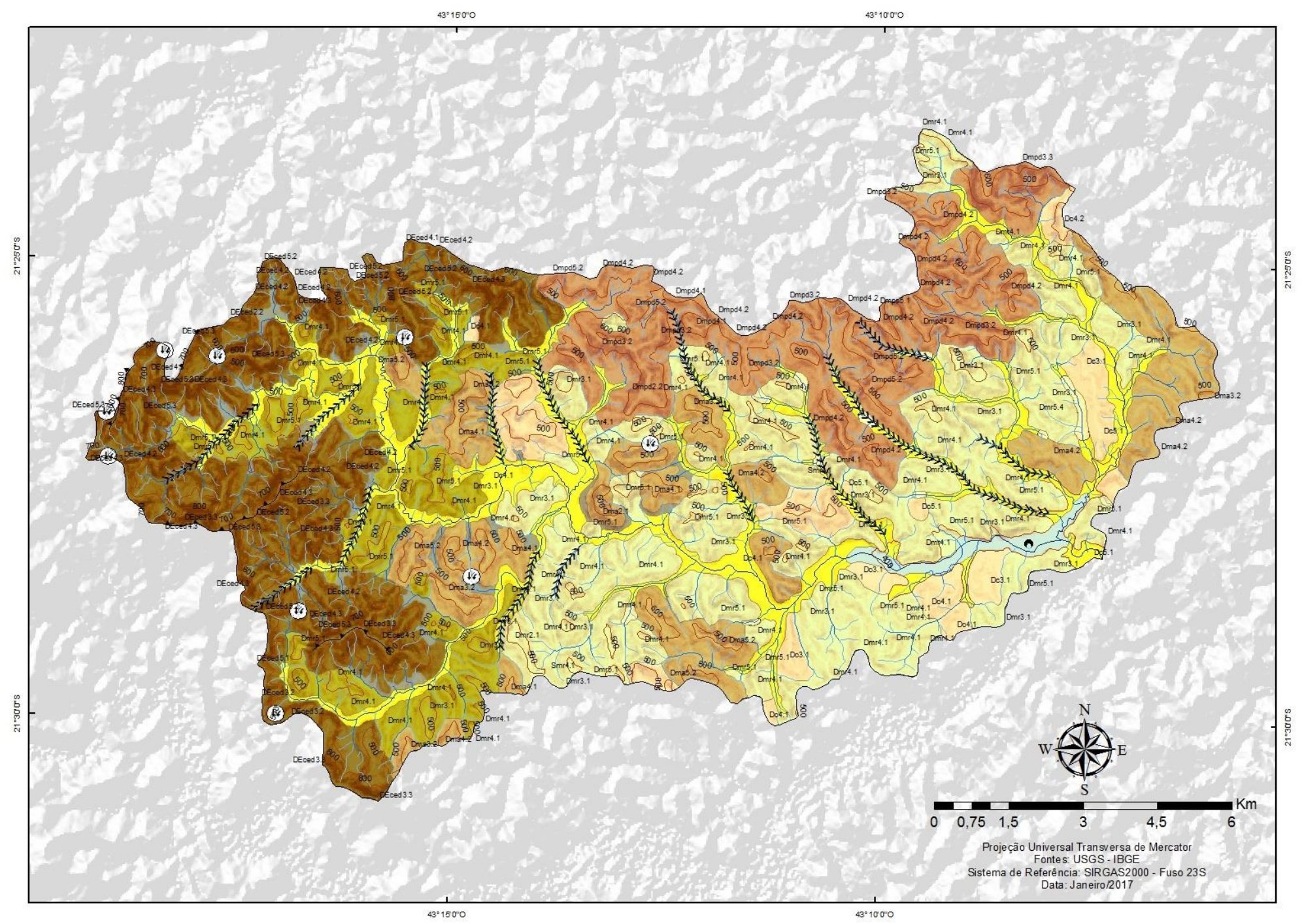

Figura 02: Carta Geomorfológica da Bacia Hidrográfica do Ribeirão Caranguejo. 
M od elados de Agradação:

\begin{tabular}{|c|}
\hline Apf \\
\hline
\end{tabular}

$$
\text { Apft }
$$

Apfla

Mod elados d e Disseca ção H om ogênea:

\begin{tabular}{l|l|l|l|l|l} 
Dmpd & Dma & Dm c & Dm r & Dprm & Dc \\
\hline
\end{tabular}

M od elado de Disseca ção E strutural:

MODELADOSDE AGRADAC̣ÂO (A):

PLANICIES FLUVIAIS (Apf): Áreas planas resultantes de acumulação fluvial sujeita a imundações periódicas, corre spondendo às vairzeas atuais. Ocorrem nos vales com preenchimento aluvial.

PLANICIES FLUVIAIS E TERRAÇOS (Apft): Areas planas resultantes de acumulação fluvial, periodicamente alagadas, comportando meandros abandonados e cordões arenosos. Ocorrem nos vales com preenchimento aluvial, contendo material fino a grosseiro, pleistocênico e holocênico. São identificados em conjuntos devido à limitação de repre sentação nesta escala de mapeamento.

PLANICIES FLUVIO-LACUSTRES ANTROPOGÊNICAS (Apfla): Áreas planas resultantes de processos de acumulação fluvial e lacustre antropogennica, podendo comportar canais anastomosados, paleomeandros e diques marginais. Ocorre em setores sob efeito de processos combinados de acumulação fluvial e lacustre oriundas de processos antropogênicos sujeito a inundações periódicas com barramentos, formando lagos.

RAMPAS DE COLÚVIO (Arc): Formas de fundo e vale suavemente inclinadas, associadas à coalescência de depósitos coluviais provenientes das vertentes que se interdigitam, ou recobrem os depó sitos aluvionares.

\section{MODELADOSDE DISSECACุ̃̃O HOMOGÊNEA (D):}

MORROS PROFUNDAMENTE DISSE CADOS (Dmpd): Morfologias mamelonares quaternárias profundamente dissecadas. Ocorrem vinculadas a alguns interflúvios.

MORROS AL ONGADOS (Dma): Morfologias mamelonares quaternárias com formato alongado.

MORROS CONVEXOS(Dmc): Morfolog ias mamelonares quaternárias com formato tendendo ao arredondado.

MORROTE S (Dmr): Morfologias mamel onares quaternárias rebaixadas.

PATAMARES REAFEICCOADOS EM MORROTES (Dprm): Patamares de relevo rea feiçoados pelo intenso processo de dissecação fluvial, dando origem a morfologias com a tributos característicos de morrotes.

COLINAS (Dc): Feições de tamanho e largura variável. Ocorrem vinculadas ao morros e setores de relevo montanhoso, comportando materiais de granulome tria arenosa e argilosa, transicionam o dominio das encostas com os fundos de vale.

\section{MODELADOSDE DISSE CACCÃ OEM CONTROLE ESTRUTURAL (DE):}

CRISTAS E STRUTURAIS DISSE CADAS (DEced): Conjunto de morfologias composto por serras e/ou conjuntos de serras alongadas, sob influência de controle estrutural, caracterizada pela presença de cristas e vales estruturais.

\section{Simbologia:}

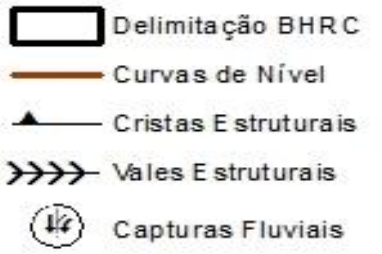

\section{Hierarquia Fluvial (Strahler, 1952):}

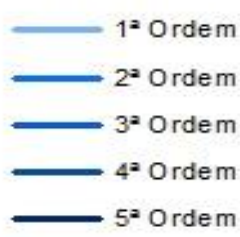

MORFOME TRIA DOS MODE LADOS DE DI SSE CAC̣ÃO

\begin{tabular}{|c|c|c|c|c|c|}
\hline \multirow{2}{*}{$\begin{array}{c}\text { Intensidade do } \\
\text { entalhe vertical } \\
\text { da drenagem }\end{array}$} & \multicolumn{5}{|c|}{ Dimensão Interfluv ial Méd ia } \\
\hline & $\begin{array}{l}\text { Muito Fina } \\
(=400 \mathrm{~m})\end{array}$ & $\begin{array}{c}\text { Fina } \\
(401 \text { a } 600 \mathrm{~m})\end{array}$ & $\begin{array}{c}\text { Média } \\
(601 \text { a } 800 \mathrm{~m})\end{array}$ & $\begin{array}{c}\text { Grosseira } \\
(801 \mathrm{al} 000 \mathrm{~m})\end{array}$ & $\begin{array}{c}\text { Muito } \\
\text { Grosseira } \\
(=1000 \mathrm{~m})\end{array}$ \\
\hline $\begin{array}{c}\text { Muito Fraca } \\
(=100 \mathrm{~m})\end{array}$ & 5.1 & 4.1 & 3.1 & 2.1 & 1.1 \\
\hline $\begin{array}{c}\text { Fraca } \\
(101 \text { a } 200 \mathrm{~m})\end{array}$ & 5.2 & 4.2 & 3.2 & 2.2 & 1.2 \\
\hline $\begin{array}{c}\text { Mediana (201 a } \\
500 \mathrm{~m})\end{array}$ & 5.3 & 4.3 & 3.3 & 2.3 & 1.3 \\
\hline $\begin{array}{c}\text { Forte } \\
(501 \mathrm{al} 000 \mathrm{~m})\end{array}$ & 5.4 & 4.4 & 3.4 & 2.4 & 1.4 \\
\hline $\begin{array}{c}\text { Muito F orte } \\
(=1000 \mathrm{~m})\end{array}$ & 5.5 & 4.5 & 3.5 & 2.5 & 1.5 \\
\hline
\end{tabular}

Figura 03: Legenda da Carta Geomorfológica da Bacia Hidrográfica do Ribeirão Caranguejo. 
Em associação às morfologias anteriormente descritas tem-se a ocorrência de algumas colinas (Dc) e morros arredondados convexos, possuindo estes formatos tendendo ao arredondado. As colinas da área de estudo são feições de tamanho e largura variável posicionadas em segmentos inferiores das vertentes. Ocorrem associadas espacialmente aos morros e setores de relevo montanhoso, comportando materiais de granulometria arenosa e argilosa. Quanto aos morros, como anteriormente mencionado, figuram como morfologias cuja gênese está associada ao intenso processo de dissecação ao qual a região vem sendo subjugada.

Nas áreas interfluviais, ao norte da bacia, tem se a ocorrência de morros profundamente dissecados (Dmpd), claramente herdados de um controle estrutural pretérito mais contundente, atualmente atacados por uma dissecação mais avançada sobre tais estruturas. Os morros existentes na bacia do ribeirão Caranguejo possuem topos alinhados, denotando a ação da intensa dissecação fluvial, sendo o isolamento dessas morfologias uma consequência do referido processo de dissecação. Todos os modelados de dissecação anteriormente mencionados figuram como morfologias mamelonares produtos da dissecação quaternária.

Os modelados de dissecação em controle estrutural são representados por morfologias de tipicidade montanhosa nas proximidades das cabeceiras, na alta bacia. Esse conjunto de morfologias é composto por serras e/ou conjuntos de serras alongadas, sob influência de controle estrutural, caracterizada pela presença de cristas e vales estruturais. Associadas às referidas morfologias tem-se a ocorrência de rampas de colúvio (Arc), sendo estas caracterizadas como formas de fundo e vale suavemente inclinadas, associadas à coalescência de depósitos coluviais provenientes das vertentes que se interdigitam, ou recobrem os depósitos aluvionares.

Além das rampas de colúvio, compondo a categoria dos modelados de agradação foram identificadas na bacia do ribeirão Caranguejo três categorias de planícies: (1) As planícies fluviais (Apf), sendo caracterizadas por áreas planas resultantes de acumulação fluvial sujeita a inundações periódicas, correspondendo às várzeas atuais e tendo sua ocorrência vinculada aos vales com preenchimento aluvial; (2) As planícies fluvio-lacustres antropogênicas (Apfla), que tem sua gênese associada aos processos de acumulação fluvial e lacustre antropogênica, sendo sujeitas a inundações periódicas e com barramentos, formando lagos; (3) Planícies fluviais associadas a terraços, que têm sua ocorrência circunscrita aos vales com preenchimento aluvial, contendo material fino a grosseiro, pleistocênico e holocênico. São identificados em conjuntos devido à limitação de representação nesta escala de mapeamento.

\section{CONSIDERAÇÕES FINAIS}

Através da metodologia de análise geomorfológica empregada inferiu-se a ocorrência na bacia hidrográfica do ribeirão Caranguejo de três tipos distintos de modelados compondo a 
paisagem regional: modelados de agradação (planícies fluviais associadas ou não a terraços, planícies fluvio-lacustres antropogênicas e rampas de colúvio), modelados de dissecação homogênea (morros profundamente dissecados, morros alongados, morros convexos, morrotes e colinas) e modelados de dissecação estrutural (cristas estruturais dissecadas).

A partir dessa classificação e espacialização dos fatos geomorfológicos, torna-se viável o discernimento acerca das possibilidades e restrições impostas pelo relevo local à ocupação e desenvolvimento de atividades econômicas, tornando a presente comunicação um salutar instrumento para a tomada de decisão no que tange às distintas esferas do planejamento na região da Zona da Mata Mineira. Por fim, intenta-se que o mapeamento ora apresentado possa auxiliar no aprimoramento da metodologia utilizada, bem como abrir novas perspectivas para a pesquisa geomorfológica na região em questão.

\section{REFERÊNCIAS BIBLIOGRÁFICAS}

AB'SÁBER, A.N. O domínio dos mares-de-morros no Brasil. Geomorfologia 2, IGEOG-USP, S. Paulo, 1966.

ARGENTO , M.S.F. ( 1995 ) Mapeamento geomorfológico. In: GUERRA, A. J. T.; CUNHA, S.B. da (org.) Geomorfologia: Uma atualização de bases e conceitos. Rio de Janeiro, Bertrand Brasil.

COLTRINARI, L. Cartografia geomorfológica detalhada: a representação gráfica do relevo entre $1950 \mathrm{e}$ 1970. Revista Brasileira de Geomorfologia, v. 12, número especial, p. 121-129, 2011.

CHRISTOFOLETTI, Antonio. Modelagem de Sistemas Ambientais. São Paulo: Edgard Blücher, 1999.

CUNHA, C. M. L.; MENDES, I. A.; SANCHEZ, M. C. A cartografia do relevo: Uma análise comparativa de técnicas para a gestão ambiental. Revista Brasileira de Geomorfologia, Ano $4, \mathrm{n}^{\circ} 1$, 2003. Disponível em: < http://ugb.org.br/home/artigos/SEPARATAS_RBG_Ano_2003/Revista41_Artigo01_2003.pdf>. Acesso em: janeiro de 2017.

INSTITUTO BRASILEIRO DE GEOGRAFIA E ESTATÍSTICA (IBGE) - Fund. IBGE, Manual Técnico da Vegetação Brasileira. Coordenação de Recursos Natural e Estudos Ambientais. Rio de Janeiro, 2012.

RADANBRASIL. Ministério de Minas e Energia (1983). Levantamento dos Recursos Naturais Folhas SF 23/24 Rio de Janeiro/Vitória. Rio de Janeiro, v.32 (escala 1:1.000.000).

ROSS, J. L. S. Geomorfologia: Ambiente e Planejamento. São Paulo, Contexto, 1991.

ROSS, J. L. S. O registro cartográfico dos fatos geomórficos e a questão da taxonomia do relevo. Revista do Departamento de Geografia, São Paulo, FFLCH - USP, n.6, 1992.

TRICART, J. Principes et méthodes de I geomorphologie. Paris: Masson Ed., 1965.

VALVERDE, O. Estudo Regional da Zona da Mata, de Minas Gerais. Rio de Janeiro: IBGE, 1958. 